\title{
Analysis of the Systematic Risk of Financial Institution in Modern Finance Evolution
}

\author{
Yun Zhang \\ Nanjing Institute of Industry Technology, Nanjing 210046, China \\ E-mail: rossa0897@sina.com
}

\begin{abstract}
Starting from the resourcing of credit, the instability of financial institution induced by the behaviors of financial institution is analyzed in this article, and the source of the systematic risk is proposed, which indicates that the change of the international monetary system is very important for the stable management of financial institution.
\end{abstract}

Keywords: Credit, Financial institution, Systematic risk

\section{Financial institution is the production factory of credit}

From the essential description of the financial system, the core content should be the derivation mode of credit and the organization mode of the production and reproduction taking credit as the production factor, i.e. the credit is regarded as the resource. In another words, financial institution is the production factory of credit, i.e. the raw material of production is credit, and the output of production is credit, and when the credit resource is produced to be product and the sales is completed, i.e. when the credit process and the credit form transfer, the intention that the individual appeals to financial institution is realized, but as the credit production factory, the financial institution seeks for its own high profit.

\subsection{The Creation base of credit}

In the informationization time nowadays, the credit is regarded as the "symbolized value wandering soul" leaving the matrix. "Symbolization" represents standardized and exact abstract particularity in the advanced life world of the informationization society, and this particularity makes the value break away from the complex value carrier of the entity economy, and go back to the "common credit flow" of the financial system. Without loss of generality, the essential form of credit is the value carrying taking the contract achievement as the orientation.

\subsection{The duality of credit}

When the contract is more essential than the value what it carriers, for example, when it is the credit resource, the coagulation form of the contract to the value is the credit with the senior form. That is to way, the credit is the content that the contract explains. For any party of the contract, his credit is represented by the form of "credit accumulation", but the credit of the other party is represented by the "credit consumption" which is waiting to be consumed.

Taking the loan contract as among natural persons as the example, the fact of credit accumulation means guaranties, and the credit consumption is the loan line. They have different status, and largely different value lines. Before the contract works out, the credit consumption line evaluation based on the credit accumulation is the important factual economic activity. Its initiative party is in loaner, and the lender is generally in the passive status who could only accept something. Even so, the loan contract doesn't disobey the fact of equivalence exchange.

Once the credit contract becomes effective, the credit accumulation and the information consumption could be coagulated, i.e. the primary economic activity is "bracketed", and when this contract enters into the contract market by the form of resource, the economic fact in the bracket will be forgot by the contract market which only is interested in the symbolized bracket, and the credit accumulation will be accumulated again.

\subsection{Resourcing of credit of financial institution and conditions}

The credit dissociates from the "body" with the commodity form, the undertaker of concrete value, and this symbolized abstraction makes all "values" with potential meanings could be evaluated by the form of credit. This evaluation is to adopt the visual evaluation mode in the economic exchange behavior to complete the activation of the value of the undertaker of the generalized value, i.e. the mortgage realization. But the realization of the value activation is the implementation of the attribute of the credit consumption.

Generally speaking, the credit accumulation is a certain quantity in one economic activity, such as the estate and the future income in the normal status. The premise that the credit consumption comes into exist is the contract 
achievement. In the financial market, the credit contract with concrete contents becomes the credit bill with abstract symbolization, which completes one qualitative change of credit. The profound connotation of this qualitative change lies in the introduction of the third party independent of two parties of credit, i.e. the financial institution.

In the early historical development of the endless equivalence exchange and the loan among individuals, the credit exchange was only the expansion of the connotation of the commodity exchange, and the essential didn't exchange. Including the professional loan behaviors in the native banks and hockshops with the character of early bank, two parties of trading only have the equal attribute of natural economic person. After the independent agency which took the bill, not the content of bill, as the data resource to engage in the financial innovation, the modern development of credit had the financial meaning.

The modern financial institutions are the derivative product of credit, and they are the development and innovation institutions of the credit resources, and their essential behavior is to derive new credit consumption lines taking the form bill as the guaranty. This new derivative credit could not undertake by the bill any longer, because the bill has completed the credit payment, and it carries no new values. So the derivative new credit value could only be undertaken by another carrier, i.e. the financial institution. In another words, the derivative credit of financial innovation is the institution credit consumption taking the credit of the financial institution as the guaranty.

\section{Systematic risk of financial institution}

\subsection{Stability of the operation system taking the credit resource as the object}

Financial institution belongs to special enterprise, and it takes the symbolized credit form abstracting from values as the basic resource to complete the production and reproduction process of credit. The production process of credit is the affixation of simple credit values, and the reproduction of credit is the credit derivation costing the credit consumption ability of financial institution.

In the situation of derivate financial system, the maximization target is the maximization of the derivative credit consumption line, and the essential of the maximization of derivative credit is to package the credit of financial institution to the maximization form.

The credit derivation operation system is the core of the work machine of financial institution. The instability of this system will directly bring the failure of the credit production line, even getting in the crisis of bankruptcy. Therefore, the stability of the operation system is the first component for the financial enterprises.

Many technical criterions determine the stability of the system. But the key problem is that whether the design principal of the program operation system accords with the practical system behavior mode. Though the treatment object of the system is abstract credit data, the live economic life is concealed in the credit contract. If the treatment mode of the operation program system to the credit falls away from the practical validity of the practical economic life, program designers will certainly face the real crisis.

\subsection{The "herd effect" in the operation system}

The work principle of the operation program of the financial system is based on many hypotheses of many conditions. The most basic hypothesis is that the random hypothesis exists among cases of credit trading. The so-called randomness among individual cases means that they are independent events without associations influencing each other. This point is the first premise of the random process analysis, and only in this way, the legitimacy of the probability statistics could be kept.

The stochastic hypothesis will be profoundly disintegrated in practical economic activity, because once the society has the sufficient condition of information, the economic activities will be infected by mutual decision favors. Furthermore, this kind of infection doesn't make the system return to the stability, but go to structural shock. This is another deviation of the control theory model to the social behaviors, i.e. the control theory is used to and is absorbed in the model treatment of the negative feedback mechanism, and the negative feedback is the mechanism to adjust the system to the stability. This mechanism supposes that people would intelligently allocate their assets to the non-hot aspects and spontaneously realize the reasonable resource allocation. In economics, this mechanism was called as "invisible hand" by Adam Smith, and it is the theory source that the market allocates resources. But in practical human group behavior mode, this mechanism is often disintegrated by another mechanism, i.e. the mechanism of positive feedback often reflects the mutual influences of behaviors. It is the reverse mechanism of the negative feedback mechanism, which is called as the "herd effect" in economics, and it is the sign of selecting irrational decision, but the normality in the practical economic life. This effect often pushes the whole system to fluctuate structurally, and makes the system loss the stability. 


\section{The form and system recovering of financial crisis}

\subsection{The finance system as the economic service system}

Financial institution is the institution-for-itself by the form of enterprise, and it pursues the self-discipline restriction of self-system, but the fate of financial institution is different than general production enterprises, because its credit resource and credit output come from and serve for the whole society. The credit is the abstract "basic data" by the form of credit flow for financial institution, and it aims at the description of the credit production process of financial institution, but in the real economic world, the abstract credit is real capitals, and the credit flow in the financial operation process is the important cash flow like blood in the practical economic life. Therefore, the social function of financial institution is the social service system which is as important as the blood in the body to the heat. The society needs and depends on the stability and high-efficiency of this service system, and is hard to assume the fluctuation and structured swing of this system.

This is the profound social reason that the financial enterprises must accept the social regulation and limitation, and they should only be single profitable institution. Nay, as the state institution of effective regulation, the central bank is the undertaker of the highest financial risk in technically controlling the operations of financial institution (such as base interest rate and reserve), and when it offers the credit guarantee for common financial institution, it even needs to be guaranteed by the state sovereignty.

\subsection{The root of financial crisis and the systematic recover of the financial institution}

From the essential attribute of the credit production of financial institution, the roots of the crisis should be in following three kinds of conflict.

The first one is the conflict between the credit production attribute of financial institution and the service attribute of function. Its direct reflection is the design deficiency of the operation program system. Obviously, the conflict exists between the output maximization target of credit production and the social benefit maximization target of service economy. Including financial institution, each one rational member understands this concept, i.e. only to effectively serve the society could effectively realize the sustainable growth of itself. But this concept faces large paradox in theory, i.e. the design project with the comprehensive optimal system of these two targets doesn't exist. In practice, the professional financial institution is designed according to the benefit maximization, and the central institutions and regulation institutions are regulated by the social benefit principal of service.

The second one is the conflict between the self-organization allocation mode as the essential form of value and the passive accepting financial institution system operation allocation mode as the abstract form of resource. If there are no drivers to push the potential values in the practical economic life, most financial functions have no spaces to be used. So financial service is the movement activator of statistic value, but that doesn't mean without the participation of financial institution, the statistic value has not the ability of self-movement. On the contrary, the movement is the most instinct and basic attribute of value, and before the financial institution occurred, the form of self-movement of value had companied with people for thousands years. Therefore, the value except for the form of credit has the initiative to allocate resource by itself, but once this initiative enters into the financial operation system by the abstract form, it would passively accept the allocated resources. The initiative of value and the passivity of resource will be exhibited rounding generalized financial activities, which will induce the difficulty that the financial operation system allocates resources. Once the value initiatives of passive resources resonate by the form of "herd effect", financial institution will not endure the structured impact.

The third one is the conflict between the infinite developments of credit resourcing of financial institution induced by the continual derivation of credit and the instinct limitation of credit resource. Financial institution digs the credit resource by the maximization mode, and for financial institution, the credit resource will be in the deficient state for ever. To compensate the deficiency of resource, financial institution will select the financial innovation of derivative credit. Financial innovation cuts the value association between the real credit and the visual credit, which equals to guarantee the derivative credit exceeding the real credit by the mode of institution credit. In fact, the derivative credit is the mortgage payment of the institution credit. When the institution credit could not pay the infinite visual development of the derivative credit, the financial crisis will not be avoided.

That also indicates that the infinite development of institution guaranty will develop to the super-financial crisis in the sovereignty game. When the financial derivative products of the sovereignty state have to be guaranteed by the sovereignty in the safe status, in the finance, the sovereignty institution will cover its own financial risk, and forcedly develop all internationalized credit resource, which may avoid its own crisis, but will certainly brew deeper international financial crisis, so the change of the international monetary system is urgently important for the stable management of financial institution in financial system. The game among sovereignties will more 
indicate the instinct conflict between the sovereignty game and the human justice, which always exceeds the finance, even the economics.

\section{References}

Bai, Qinxian. (1999). Challenge and Revelations of the Economic Globalization and Economic Financing. World Economy. No.6.

Chen, Piaoru. (2000). International Finance. Chengdu: Press of Southwestern University of Finance and Economics.

William A. Fleckenstein \& Frederick Sheehan. (2008). Greenspan's Foam. Beijing: China Renmin University Press.

Zhang, Yun, Kong, Bingbing et al. (2009). Direction Selection after the Bretton Woods System. Modern Business. No.32.

Zhang, Yun \& Yu, Zhonghua. (2009). International Monetary System Reform from the View of "Multi-Layer Equipollence Theory". Contemporary Economics. No.18. 